\title{
Towards impact measurement: An overview of approaches for assessing the impact of academic literacy abilities
}

\author{
Ilse Fouché
}

Four-year Programme, University of Pretoria, South Africa

E-mail: ilse.fouche@up.ac.za

\begin{abstract}
A variety of academic literacy interventions are used at higher education institutions to address the low level of academic literacy with which many students enter these institutions. Considering the increasingly resource-scarce higher education environment, it is becoming crucial for those who are responsible for such interventions to provide evidence of their impact on student success. The aim of the current study is to provide a broad overview and critique of studies conducted thus far that attempt to assess the impact of various academic literacy interventions. This study proceeds by identifying instruments that are commonly used when assessing the impact of these interventions. From the literature surveyed, it would seem that there are two broad aspects that are considered when evaluating impact, namely students' improved academic literacy levels between the onset and the completion of the course, and the extent to which these acquired academic literacy abilities are transferred to students' other subjects. The next step in this research project will be to propose a comprehensive evaluation design that could be used by a range of academic literacy interventions.
\end{abstract}

Keywords: academic literacy, programme evaluation, impact measurement

\section{Introduction}

It is generally acknowledged that the South African secondary education system does not sufficiently prepare students for higher education studies (Cliff 2014:322; Van Dyk, Zybrands, Cillié and Coetzee 2009:333; Higher Education South Africa 2008:3). One consequence of this is poor university throughput rates, with as many as $55 \%$ of all enrolled students leaving university without graduating, and only $27 \%$ of all students graduating their 3 - and 4-year qualifications in the prescribed time (Scott, Ndebele, Badsha, Figaji, Gevers and Pityana 2013:43). A prominent factor identified among students who are underprepared for higher education studies is a low level of academic literacy. Researchers almost unanimously agree: adequate academic literacy (which includes, but is not limited to, language proficiency) is crucial to students being successful in their studies (Terraschke and Wahid 2011:173; Defazio, Jones, Tennant and Hooke 2010:34; Leibowitz 2010:44; Davies 2009:xi; Archer 2008:248). 
Based on the aforementioned research, it would seem that a large number of students needs academic literacy support. This number grows each year, mainly due to the massification of higher education which inevitably implies more underprepared students gaining access (see Calderon 2012 and Teichler 1998 for a comprehensive discussion of this trend). Yet universities seem to have fewer and fewer resources available each year (see, for example, Hornsby and Osman 2014:712-713; Kwiek, Lebeau and Brown 2014:6). This is possibly why "attention has shifted [in recent years] from an almost exclusive focus on access to include a concern with graduation rates and with general efficiency and quality matters" (Yeld 2010:26). In order for the existence of academic literacy programmes to be justified in this resource-scarce higher education environment, they need to be able to show that they have a real and worthwhile impact on student success.

Impact assessment falls under the umbrella term of "programme evaluation" (De Vos, Fouché, Strydom and Delport 2011:453). Situating it in an educational context, Brown (2001:15) defines programme evaluation as "the ongoing process of data gathering, analysis, and synthesis, the entire purpose of which is constantly to improve each element of a curriculum on the basis of what is known about all of the other elements, separately as well as collectively". De Vos et al. (2011:449) argue that "[i]n an age of accountability, [stakeholders] demand that some evidence is provided in terms of 'what works', 'how it works' or 'how it can be made to work better"'. This seems to be especially true in the resource-scarce South African higher education environment where the majority of students need effective academic literacy support. Academic literacy support can only be made more effective if we can determine which abilities are acquired most effectively by students and what academic literacy specialists are doing right to facilitate this acquisition, in addition to which abilities are not being acquired optimally. Only when academic literacy specialists can identify the weak points in a curriculum can they strive to responsibly improve their interventions.

When evaluating language programmes, Lynch (2003:1) points out that the areas of language assessment and programme evaluation usually overlap in that data from language assessment are often used as part of programme evaluation in order to make decisions and judgements, reflect, and ultimately take certain actions. Bachman and Palmer (2010:21) agree: "Evaluation involves making value judgments and decisions on the basis of information, and gathering information to inform such decisions is the primary purpose for which language assessments are used".

Two main specific purposes of programme evaluation in educational contexts are firstly to determine whether the programme is achieving its objectives, and secondly to determine which links exist between the processes of the specific programme and students' achievement (Lynch 2003:2). By doing this, it should be possible to determine how effective specific components of the intervention are (Lynch 2003:7), and thus to find ways of improving the programme being evaluated (Newcomer, Hatry and Wholey 2010:6). In fact, argues Brown (2001:15), one should probably view the evaluation process as an ongoing needs assessment so as to constantly improve the programme in question (cf. Bachman and Palmer 2010:25).

As mentioned before, impact assessment addresses a very specific, though central, facet of programme evaluation (De Vos et al. 2011:453). Programme evaluation could include a myriad of factors, such as cost-effectiveness and work satisfaction of teachers and lecturers. While evaluating the impact of a programme or intervention would almost always be part of programme evaluation, impact assessment is a distinct facet that needs to be examined separately. 
It should be kept in mind that there are various challenges to determining the impact of academic literacy interventions. One such challenge is that these interventions come in all shapes and sizes, for example, generic interventions, subject-specific interventions, undergraduate interventions, postgraduate interventions, reading interventions and writing centres - examples of all of these are discussed later in this article. This wide variety of academic literacy interventions makes it difficult, if not impossible, to assess impact by using a uniform approach. A further challenge is that the use of control groups, which would be part of traditional experimental designs, is often unfeasible in the South African context where, increasingly, all students (at least at first-year level) are required to participate in some type of academic literacy intervention. Many studies attempting to assess the impact of academic literacy interventions must thus find other ways of providing reliable and valid results.

For the purposes of the current study, the terms "impact" and "effect" will be viewed as synonymous. De Graaff and Housen (2009:727) define these as "any observable change in learner outcome (knowledge, disposition or behavior) that can be attributed to an instructional intervention (possibly in interaction with other, contextual variables)". An intervention's effectiveness, then, "refers to the extent to which the actual outcomes of instruction match the intended or desired effects" (De Graaff and Housen 2009:727-728). It is, however, important to keep in mind the following observation by Cheetham, Fuller, McIvor and Petch (1992:9-10):

\begin{abstract}
Despite much apparently straightforward use of the word, 'effectiveness' is not something which has an object-like reality 'out there' waiting to be observed and measured. Like any other data, empirical evidence about the effectiveness of [...] programmes is a product of data collection procedures and the assumptions on which they are based. The concept of effectiveness derives from particular ways of thinking and makes sense only in relation to its context. [...] The challenge is to arrive at working definitions of effectiveness in specific situations, and hence of methods of studying it, which do not permanently lose sight of its conceptual context.
\end{abstract}

Keeping the above argument in mind, impact (or effect) will, for the purposes of the current study, be seen as i) the observable improvement in academic literacy abilities between the onset and the completion of an academic literacy intervention, and ii) the extent to which these abilities are necessary and applied in students' content subjects.

This article forms part of a larger study which aims at developing an evaluation design that could be used to assess the impact of academic literacy interventions in the South African context. The aim of this article is to provide an overview and critique of studies conducted thus far that have attempted to assess the effectiveness of various academic literacy interventions; this article is therefore conceptual in nature. The next step in this study will be to propose a conceptual evaluation design that could be used for various types of academic literacy interventions, based on the literature that is reviewed in the current article. This design will then be validated and verified in subsequent phases of this study by i) using it to assess the impact of an academic literacy intervention, and ii) asking academic literacy course/intervention coordinators across the country about the extent to which the proposed evaluation design meets their needs, and how it could be refined to be applicable for their specific contexts. After refining the design, a final evaluation design will be proposed. 


\section{Previous studies on the impact of academic literacy interventions}

Before considering in detail the studies that have reported on impact, it is worthwhile to distinguish between "language programmes" and "academic literacy interventions". As the term implies, the focus of language programmes is on students' language, and very often these programmes focus on the language abilities of second language users. Academic literacy programmes, in contrast, include (but are not limited to) language ability (Van Dyk and Van de Poel 2013:53). This study accepts Van Dyk and Van de Poel's (2013:56) definition of "academic literacy" as "being able to use, manipulate, and control language and cognitive abilities for specific purposes and in specific contexts". Due to the dearth of studies measuring impact in either language programmes or academic literacy interventions, this article considers studies from both of these fields.

Studies measuring the impact of academic literacy and language courses are indeed few and far between (Mhlongo 2014:47; Terraschke and Wahid 2011:174; Carstens and Fletcher 2009b:319; Storch and Tapper 2009:208; Holder, Jones, Robinson and Krass 1999:20). Yet, argues Butler (2013:80), in addition to having a theoretical justification for the type of intervention that is developed, the intervention's success is ultimately determined by the impact it has on students' learning. Some South African as well as international studies have been able to effectively measure certain aspects of such an impact. As is seen in the survey below, most of these studies focus on only one or two aspects of impact. However, as Beretta (1992:19) states, no single methodology can provide a full picture when it comes to the evaluation of language programmes (for example, academic literacy programmes). A comprehensive, validated and verified evaluation design might assist researchers in choosing a more comprehensive range of tools in order to determine the impact of academic literacy courses. An overview of studies that have attempted to measure the impact of academic literacy courses, in one form or another, follows below.

Parkinson, Jackson, Kirkwood and Padayachee (2008) evaluated a course called "Communication in Science" taken by students in a science access programme at the University of KwaZulu-Natal. In their evaluation, a pre-test/post-test design was employed, using a placement test consisting of multiple-choice questions, cloze questions and writing elements. The test aimed to measure students' ability to read for meaning, extrapolate and apply information, infer information, separate essential and non-essential information in a reading text, and extract and interpret information from texts to use in an extended writing task. This test was also taken by mainstream students at the beginning of the year, though there was no post-test for these students. Secondly, a questionnaire was given to students at the end of the year to determine their opinions of the course. Perceived improvement was assessed by asking students whether they learned "a lot", "a little" or "nothing" with regard to several outcomes. Thirdly, students who had previously completed the course were given a questionnaire to determine whether they believed that the competencies acquired in the academic literacy course were of value in their subsequent studies. These students were asked the following question via e-mail: "Since completing the Communication course, in what ways have the skills you have learnt in Communication in Science been useful to you?" (Parkinson et al. 2008:23).

The results showed that access students improved significantly over the duration of the course, and in some cases even got scores close to those of the mainstream students at the beginning of the year. However, since no post-test was written by the mainstream students, it was impossible 
to determine whether they had also improved equally despite not having undergone the intervention. As far as students' perceptions of the course are concerned, findings showed that students generally enjoyed the course, and believed that they had learned a lot in the various sections. Thirdly, more senior students who had completed the course previously mostly responded that the course had been beneficial to them. Even though a control group was not available in the Parkinson et al. (2008) study, the research design was strengthened in that more validity was given to findings through triangulation. However, certain aspects of the evaluation design could have been addressed more comprehensively. For example, students' perceptions might have been ascertained more effectively. The question that was asked could be considered to be leading as it did not allow students to state which abilities were not useful; more detailed and extensive questions could have been asked to determine which abilities addressed in the academic literacy course were used in further studies, and to which extent they were used. The placement test could also have been analysed to determine in which areas students had improved the most over the duration of the academic literacy course, and these findings could have been correlated with students' perceptions about how much they had learned in the course. Thus, triangulation could have been strengthened in various ways.

Van Dyk et al. (2009) took various steps to determine whether an academic literacy intervention in the Health Sciences at Stellenbosch University had an impact on students' writing abilities. Students firstly completed pre-, mid- and post-intervention writing assignments. Results were analysed quantitatively by correlating them with each other. Assignments were also examined by lecturers who noted the difference in execution between the pre- and post-assignments and listed typical errors for both of these assignments. Writing was considered at both the micro level (including language and word choice) and macro level (including paragraph structure, cohesion and coherence, and argumentation). Students' writing at both of these levels seemed to have improved between the pre- and post-intervention writing assignments. This qualitative feedback was the most useful feedback in this particular study; however, a weakness was that the evidence remained mainly anecdotal, consisting of lecturers' impressions. Finally, students completed feedback questionnaires on, amongst others, the relevance of material and the learning outcomes. This feedback consisted of many more positive than negative qualitative comments. A limitation might have been that the questionnaire took the form of an official student feedback form. This means that the questionnaire was designed mainly to measure students' perceptions of the course itself and the way that it was presented. Such official feedback forms are often the only tools available to lecturers to gauge perceptions on specific courses. However, they rarely allow lecturers to assess which aspects of the course students found most useful, and to what extent the course was likely to impact on their general academic success. The purpose of this study was to determine the impact that the course had on students' writing abilities, and thus a writing assignment was suitable. The different forms that the three writing assignments took, however, made it difficult to draw direct comparisons, as would be the case in a pre- and post-assignment scenario where two or more equivalent assignments with the same outcomes are used.

Van Dyk, Cillié, Coetzee, Ross and Zybrands (2011) reported on a study conducted at Stellenbosch University that focused on the effect of an academic literacy course in the field of natural sciences on students' reading levels. The study consisted of quantitative data in the form of a pre- and post-test (aimed at assessing students' reading abilities), an online questionnaire that aimed to determine which reading abilities students believed to be important in order to be successful in their studies, as well as official student feedback forms. The Test of Academic Literacy Levels (TALL) and its Afrikaans equivalent, Die Toets van Akademiese 
Geletterdheidsvlakke (TAG), were used as pre- and post-tests. The test construct of these tests measures the following: understanding academic vocabulary; interpreting metaphor, connotation and ambiguity; understanding relations between parts of a text; interpreting and showing sensitivity to various text types; interpreting, using and producing visual information; making distinctions between various types of information; seeing sequence and order; understanding evidence used in texts; understanding the communicative functions of ways of expression in academic language; and making meaning beyond sentence level (see Weideman 2003:xi for a more detailed description). Qualitative data consisted of open-ended questions in the official student feedback forms.

Results showed that the impact of the academic literacy course becomes clearer after a year's intervention than after a semester's intervention, indicating that long-term interventions might be more beneficial to student success than short-term interventions. Feedback from student questionnaires indicated that students believed that reading abilities were important for a student to be successful in his/her studies, that the module achieved its outcomes, and that necessary academic literacy abilities were developed. In this study, the use of a valid and reliable academic literacy test enabled conclusions based on statistical analysis that were not possible in the Van Dyk et al. (2009) study. However, similar limitations as in the previous study exist. For example, official feedback forms are possibly not the most effective way of assessing the impact of a course. Furthermore, the study is limited to assessing reading levels, whilst other academic literacy abilities might also have improved over the duration of the course; thus, using a wider variety of assessment instruments might have been useful.

Mhlongo (2014) assessed the impact of an academic literacy intervention at the Vaal Triangle Campus of the North-West University. He made use of the same academic literacy test that was used in the Van Dyk et al. (2011) study - i.e. the TALL - but also drew on the perceptions of students as well as mainstream lecturers who taught first-year students by administering questionnaires developed for this purpose. He further drew a correlation between students' overall academic achievement and their academic literacy levels. A particularly useful aspect of this study was the use of a control group. All students who obtained below 50\% for the TALL were required to participate in the academic literacy course, whereas students who obtained $50 \%$ and above were exempted - it would thus seem as though the formation of a control group might have been difficult. Mhlongo (2014), however, used two groups of students: those who obtained between $40 \%$ and $49 \%$ (and who thus participated in the intervention - the experimental group) and those who obtained between $50 \%$ and $59 \%$ (thus those who were exempted from the academic literacy course - the control group). By using two groups of students who obtained similar marks as experimental and control groups, certain statistical conclusions could be made about the impact of the academic literacy course on student success.

Mhlongo's (2014) study indicated that there was a statistically significant improvement in the experimental group's mean scores between the pre- and post-tests. Furthermore, his results indicated that there was no such improvement in the control group students' scores. Student feedback was generally positive, although some students indicated that the courses were not relevant to their studies. Some students also indicated that more time needed to be allocated to the modules. Feedback from content-subject lecturers indicated that these lecturers were largely unaware of the abilities addressed in the academic literacy course. Furthermore, they did not seem to think that the academic literacy course made a substantial difference to their students' academic literacy levels. In addition, lecturers felt that generic academic literacy courses were 
not ideal, as they believed their own disciplines to be very different from other disciplines. They also did not believe that it was their responsibility to help students acquire academic literacy abilities.

Carstens and Fletcher (2009b) evaluated a subject-specific essay-writing intervention for history students at the University of Pretoria. The intervention was assessed by means of a preand post-test (in the form of an essay) as well as student responses regarding their perceptions of the course. A seven-point scoring rubric was used for the pre- and post-test, with percentages to give the assessor a clear idea of a benchmark for each mark allocation. The scoring instrument is based on three analytical rating scales that are internationally accredited. The following four dimensions are addressed by the scoring instrument: use of source material, structure and development, academic writing style, and editing. An N/A option was given for items which are not relevant in all types of writing (for example, referencing, legibility or layout). According to Carstens and Fletcher (2009b:324), "the success of academic literacy interventions are equally dependent on students' experience, which are co-determinants of motivation and skills transfer". Therefore, a survey was conducted to determine the opinions of the participants. The questionnaire uses a standard five-point Likert scale. This type of questionnaire would seem more useful in comprehensively determining perceptions than the purely open-ended questions that were used in some of the studies discussed in this review.

Results indicated that students improved in three dimensions between their pre- and post-test essays. These dimensions included their use of source material, structure and development, and academic writing style. Students' editing abilities did not seem to have improved over the course of the intervention. The opinion survey showed that students were generally positive about the effect of the intervention on their writing abilities. They were also in favour of the genre-specific approach that was followed in this intervention. Furthermore, the results indicated that more attention should be paid to formality and precision in academic writing, as well as developing self-confidence to challenge authority. One limitation of this study is that only ten students completed the course, making it difficult to reach statistically significant conclusions based on this small number.

Storch and Tapper (2009) assessed the impact of an English for Academic Purposes (EAP) course presented at the University of Melbourne that was aimed at developing the academic literacy abilities that are required for successful study at postgraduate level. Student writing was assessed by means of a pre- and post-test writing task. What sets this study apart from similar studies is the type of quantitative research design used in its assessment of student writing. The study measured students' fluency by looking at words per T-unit, their accuracy by counting errors in various categories, their use of academic vocabulary by comparing student lexis to Coxhead's (2000) academic wordlist, and their text structure and rhetorical quality by using a guide developed by the authors themselves. In addition to this statistical analysis, questionnaires were distributed to gather information about students' English language use and proficiency, as well as their perceptions regarding the usefulness of the course (one open-ended question was used to determine the latter).

Quantitative results from this study showed that there was no measurable effect on student fluency; however, statistically significant improvements were observed in students' grammatical accuracy and their use of academic vocabulary. Improvements were also observed in students' text structure and rhetorical quality. Qualitative outcomes indicated that the course 
had made students more aware of various academic writing strategies. While assessing student writing quantitatively in this manner is certainly an interesting approach that merits consideration, especially when the aim is to determine a course's strengths and weaknesses, this study might have benefitted by comparing these results to those obtained from a more traditional writing rubric. Perceptions might also have been measured more effectively by asking more specific questions regarding the usefulness of the course.

Some studies evaluate impact by comparing the results of two or more courses with each other ${ }^{1}$. Harker and Koutsantoni (2005) compared the effectiveness of distance versus blended learning in a web-based EAP programme at the University of Luton. Students completed a diagnostic test that comprised a summary as well as a short essay as both pre- and post-tests. In addition, students completed formative feedback forms on what they found to be the most and least useful components of each lesson, as well as summative feedback forms on the course. Feedback forms contained both closed-ended as well as open-ended questions.

Both groups of students performed better in the short essay part of the post-test than they had in the pre-test. Blended learning students who attended more classes performed better than those who attended fewer classes. There was no significant improvement in the summary section between the pre- and the post-test. Both groups of students gave more positive than negative formative feedback. The summative feedback indicated that, when compared with the feedback from the blended learning group, the distance learning group agreed that the course addressed their needs to a greater extent, though the majority of both groups felt that they had learned valuable academic English skills. A possible weakness in this study is that the summative feedback form did not readdress the various abilities addressed during the course. There was thus no indication of how useful students considered the various abilities after having completed the entire course and having had time to reflect on these abilities. Furthermore, data from various sources were not triangulated to ultimately obtain stronger research results.

Carstens (2011a) used a quasi-experimental design to compare the pre- and post-test essay ratings of students in a generic academic literacy writing course with those of students in a discipline-specific writing course. The same scoring rubric that was used in Carstens and Fletcher (2009b) was used in this study. Carstens also used surveys to determine students' opinions of the course by looking at five dimensions: staged and scaffolded teaching and the learning model, purposeful social apprenticeship, a needs-driven syllabus, critical orientation, and skills transfer. Although both groups of students performed significantly better in the posttest than in the pre-test, students from the discipline-specific writing course outperformed those from the generic writing course. Furthermore, although both groups gave positive feedback about their respective courses, the discipline-specific group's feedback was significantly more positive than that of the generic group. According to Carstens (2011b), limitations of this type of quasi-experimental design include that the comparison might be jeopardised due to differences between the syllabi and presentation of the interventions, as well as differences between the two groups. Furthermore, the fact that the courses were presented consecutively rather than simultaneously might be problematic as designers as well as presenters might have learned from the first intervention, and thus applied corrective measures to the second intervention.

\footnotetext{
${ }^{1}$ Refer back to the discussion of Mhlongo (2014) for an alternative control group experiment.
} 
A selection of other studies that compare the results of two or more courses are shortly summarised here. Kasper (1997), at the Kingsborough Community College, compared the language course results of English second language students receiving content-based instruction to those who were enrolled in generic language programmes. Murie and Thomson (2001) considered the impact of an academic literacy course by comparing the retention rates of the students who participated in the course to those of a control group. Song (2006) compared the impact of content-based EAP courses with that of generic EAP courses at the City University of New York. In this study, the following aspects of students' receptive abilities were assessed: comprehension of the text; ability to identify main ideas, purpose and tone; and ability to analyse information and to draw inferences. As for productive abilities, students were expected to submit a portfolio containing various examples of essays in different genres completed during the semester. Furthermore, they completed an in-class essay assessment.

While there are certainly clear benefits in using an experimental approach with a test and a control group, this type of study is not possible at many universities where no equivalent control groups exist. Furthermore, universities are often hesitant to allow the use of true experimental designs due to ethical considerations. Thus, while using control groups might be preferable, an evaluation design - specifically in the South African context - would have to be comprehensive enough to still allow valid conclusions to be drawn by means of triangulation, despite the lack of appropriate control groups.

At the University of Cape Town, Archer (2008) attempted to assess the impact of a writing centre on students' writing. She used a multi-faceted approach in which she collected data by i) ascertaining students' perceptions with regard to writing centre work, ii) collecting writing centre consultants' comments, iii) considering students' grades, and iv) comparing independently assessed first and final student drafts (marked by looking at organisation, language use, as well as voice and register). Archer (2008:251) reminds us that students' "perception of improvement may not necessarily translate into demonstrably improved writing". It is therefore also necessary to empirically assess such an improvement. Archer triangulated data by looking at students' perceptions, their writing, the grades they obtained for their writing, and consultants' perceptions of the writing.

Students indicated that the writing centre intervention assisted them in focusing on the task, improving their voice and register, and improving macro- as well as micro-structural issues. Furthermore, students seemed to have a greater awareness of their own writing after attending writing consultations, and were more able to articulate their writing processes. All students passed the assignments on which they had consulted. Finally, between first and final drafts, students improved in all three areas, but most pronouncedly in voice and register as well as organisation. It should be noted that writing centres generally do not consider the full range of academic literacy abilities - their focus on writing is reflected in the methodology employed in this study. Possible weaknesses of this study include that the consultants were students and not necessarily qualified language experts (though they have undergone thorough training); moreover, variables were not controlled for, perhaps because this is particularly difficult in a writing-centre context.

Several studies that assess interventions look at these interventions from limited perspectives. Some studies focus mainly on quantitative data. Van Wyk and Greyling (2008), for example, assessed the impact of using graded readers for low-proficiency students at the University of the Free State. Students' academic literacy levels were assessed by means of the Placement Test in 
English for Educational Purposes (PTEEP) as a pre- and a post-test. These data were not triangulated with other data sources. Carstens and Fletcher (2009a) statistically analysed the improvement in students' writing abilities by looking at the pre- and post-test results of a crossdisciplinary essay writing intervention aimed at second-year students in the Humanities. Fouché (2009) described a writing centre intervention: a series of academic literacy workshops aimed at first-year students in UNISA's Science Foundation Programme. In this intervention, pre- and post-test results of an academic literacy test were compared and correlated with student attendance. The problem with this type of correlation study is that it is very difficult to control variables like student motivation; more motivated students who attend more workshops (in the context of this study, or classes in other contexts) might have outperformed less motivated students who attended fewer workshops, regardless of the number of sessions attended.

In contrast, some studies rely mainly on qualitative measures to determine course impact. Thompson (2011) evaluated an "English for Tourism" intervention, aimed at fourth-year students at a Thai university. The course was assessed using a student questionnaire to determine students' reactions to various course features, interviews with a variety of stakeholders to determine their perceptions of the programme, a teacher's log to document and reflect on various aspects of the course, and learning materials which were analysed. Similarly, Ngoepe (2007) evaluated an academic literacy course called "English and Study Skills" at the University of Limpopo. The course was evaluated by means of lecturer interviews, student questionnaires, an analysis of materials, and a survey of similar courses. Kiely (2009) evaluated English for Academic Purposes materials at a British university by means of an ethnographic study, which included interviews with students and teachers, an end-of-course questionnaire, field notes, and an analysis of learning materials. Butler and Van Dyk (2004) broadly looked at students' perceptions of an Engineering course at the University of Pretoria. They also mentioned anecdotal evidence from lecturers. Similarly, Bharuthram and Mckenna (2006) reported on students' perceptions (obtained by means of an evaluation questionnaire) of the success of a writer-respondent intervention at the Durban Institute of Technology. An important limitation of these studies is that no instruments were used to determine whether there was an improvement in students' academic literacy (or language) abilities between the onset and the conclusion of the various interventions. Also, in most cases, questionnaire and interview questions mainly focused on the course in general, and did not sufficiently consider various abilities addressed throughout the course.

Winberg, Wright, Birch and Jacobs (2013) also took a qualitative approach to evaluating the effectiveness of four discipline-specific academic literacy case studies, each of which was based on a collaborative effort between academic literacy and content-specific specialists. In the first case study, fourth-year undergraduate Science and Technology student teams were responsible for developing product prototypes. In this case study, debriefing meetings were held in which academic literacy and content-specialists reflected on what had been learned from the collaborative effort. Subject specialists had not provided any formative feedback in this case study, a factor which the authors identify as problematic. The second case study involved a collaboration between academic literacy and subject-content specialists to develop multilingual glossaries. In this case study, participants reflected on the effectiveness of these multilingual glossaries through observations at various stages during the collaboration. Furthermore, reflective semi-structured interviews were held with the subject-content specialists. These interviews were analysed qualitatively, looking for emerging themes. In the third case study, academic literacy and subject-content specialists collaborated in co-authoring a textbook aimed at giving first-year 
students "linguistic access to content knowledge in an SET [Science, Engineering and Technology] discipline" (Winberg et al. 2013:95). This collaboration was evaluated by conducting structured interviews with the co-authors, which were again qualitatively analysed. During this case study, regular meetings were also held between academic literacy and subjectcontent specialists to provide participants with a "transactional space" (Winberg et al. 2013:96). The fourth case study reported on "aimed to provide linguistic access to disciplinary knowledge through interdisciplinary collaboration involving pairs [of academic literacy and subject-content specialists in Science and Technology disciplines]". In this case study, one academic literacy specialist was partnered with a subject-content specialist - in total, twenty lecturers participated. The collaboration "entailed dovetailing curricula, developing shared classroom materials, team teaching, and designing and co-assessing tasks" (Winberg et al. 2013:97). Feedback on the success of the collaborations consisted of narrative interviews, focus group sessions, and reflective writing - these were all qualitatively analysed.

The Winberg et al. (2013) study highlights the importance of obtaining feedback from primary stakeholders - in this case academic literacy and content-subject specialists - when determining whether interventions could be considered effective. However, the strong focus on the working relationships between academic literacy and content-specific specialists at the expense of additional data leaves one wondering whether the students actually improved as a result of these interventions. These case studies might have been strengthened by, for example, considering feedback from students involved in the interventions as well as analysing quantitative data so as to consider more comprehensively the success of these interventions.

Another way in which impact has been measured is by investigating how language ability measures correlate to general academic success. A recent study by Van Rooy and Coetzee-Van Rooy (2015), conducted at the Vaal Triangle Campus of the North-West University, focused on the 2010 intake of first-year students and found that the Grade 12 results of students who achieved an average of below $65 \%$ for all subjects could not, with confidence, predict academic success at university; the Grade 12 results of students who achieved an average of $65 \%$ and higher, however, could be used as a predictor for academic success. The study further found that academic literacy tests are not good predictors of success at university level. However, this study found that students' marks in academic literacy modules were good predictors of academic success. Mhlongo (2014) similarly found a significant correlation between students' academic literacy course marks and their marks in other subjects for the 2012 intake at the same university. One question that should be raised with this type of correlation is whether the positive correlation between academic literacy course marks and content-subject marks is because higher academic literacy levels (acquired in the academic literacy course) resulted in higher marks in content subjects, or whether stronger students naturally performed better in both measurements, and weaker students poorer in both. Thus, on its own, this measurement would not seem to be useful in assessing the impact of an academic literacy intervention. However, as part of a triangulated study (as was done in the study by Mhlongo), such a measurement could provide valuable insight into the impact of such interventions.

\section{Discussion and conclusion}

To summarise, various approaches to assessing the impact of academic literacy interventions can be identified in the literature. Two main aspects of impact stand out, namely determining 
whether students' academic literacy levels had improved over the duration of the course, and establishing whether students transferred these abilities to their other subjects.

Two main approaches have been used to assess whether there was an improvement in students' academic literacy levels between the onset and conclusion of an intervention. The first is assessing whether there is an improvement in students' writing abilities ${ }^{2}$ by using a rubric (e.g. Carstens and Fletcher 2009b, Storch and Tapper 2009, Van Dyk et al. 2009, Archer 2008, Parkinson et al. 2008, Song 2006) or statistically examining features of student writing (Storch and Tapper 2009). The second is by assessing whether there is an improvement in students' academic reading abilities, often by means of a verified and validated academic literacy test (e.g. Mhlongo 2014, Van Dyk et al. 2011, Fouché 2009, Parkinson et al. 2008, Song 2006).

In addition to assessing whether there was an improvement in students' academic literacy abilities, it is also important to determine whether these improved abilities were effectively used in students' other subjects. A seemingly effective way of determining whether an improvement in test scores can be attributed to a specific intervention is to use appropriate control groups (consider, for example, Mhlongo 2014; Carstens 2011a,b; Song 2006; Harker and Koutsantoni 2005; Murie and Thomson 2001; Kasper 1997). An additional and sometimes alternative method of determining whether the abilities acquired in a course were transferred to other subjects is by determining students' perceptions regarding the impact of a course (e.g. Mhlongo 2014, Van Dyk et al. 2011, Carstens and Fletcher 2009b, Kiely 2009, Storch and Tapper 2009, Van Dyk et al. 2009, Archer 2008, Parkinson et al. 2008, Bharuthram and Mckenna 2006, Butler and Van Dyk 2004). One danger, however, is that it is very difficult to determine the reliability of perceptual data - just because students say that they have acquired (and transferred) abilities does not mean that this is necessarily the case. Further methods of determining whether improvement in academic literacy levels can be attributed to the course include interviewing stakeholders (other than students) to determine their perceptions of the intervention (e.g. Mhlongo 2014, Winberg et al. 2013, Thompson 2011, Ngoepe 2007), correlating student performance with class attendance (e.g. Fouché 2009), and correlating students' performance in the academic literacy course with their performance in their content subjects (e.g. Van Rooy and Coetzee-Van Rooy 2015, Mhlongo 2014).

An important facet of the responsible implementation of academic literacy interventions is to assess whether these interventions have a significant impact. Merely offering academic literacy interventions to bow to national and international pressure for the establishment of such interventions is not enough. Universities, departments and units that offer academic literacy interventions are responsible for ensuring that these interventions have the highest impact possible. The studies discussed in this article have all attempted to do this to some extent, which indicates that some researchers are aware of the importance of assessing the impact of academic literacy interventions. However, the variety (and sometimes inconsistency) of approaches used raises the question of what the most appropriate way would be to assess the impact of academic literacy interventions.

\footnotetext{
${ }^{2}$ Although writing and reading abilities are referred to in this study, for the sake of convenience, they should be seen as broad categories that overlap, both addressing a variety of academic literacy principles. These include being able to interpret information, collaborating with the author or audience, using conventions, being aware of cultural knowledge, solving problems, and reflecting and using language appropriately (cf. Kern 2000:16-17).
} 
Unfortunately, as Howes (2003:148) reminds us, "[r]esearch on impact in education is difficult, partly because there are typically many factors involved which are difficult to control, so that the impact of any one element in the system is hard to distinguish". This is certainly the case when trying to assess the impact of an academic literacy intervention, since there are many factors at play, for example, general exposure to academic literacy abilities in students' other subjects and possible feedback on academic literacy related issues from content-subject lecturers. Furthermore, forming a control group is not possible at many universities, as almost all students have some kind of academic literacy intervention as part of the credit-bearing programme offering. In order to meaningfully determine the impact of an academic literacy intervention, therefore, alternative research designs must also be considered.

Jick (1979) argues that a more certain portrayal of a phenomenon is provided when multiple and independent measures reach similar conclusions. Lynch (1996:60) agrees and states that "triangulation seems like an obvious strategy for strengthening the validity of evaluation findings". He adds that the possibility of bias always exists in any particular technique or source; however, using a variety of sources of evidence could potentially cancel "the bias inherent in any one source or method" (Lynch 1996:60). Therefore, by examining a variety of factors that may shed light on the agency of an academic literacy course in the ultimate improvement of students' academic literacy abilities, and the extent to which these abilities were transferred to other subjects, a more valid inference can be made regarding the causal relationship between such improvement and the academic literacy intervention.

Based on the literature discussed in the previous section as well as the definition of impact that was put forward in this article, this study proposes that in order to determine the impact of an academic literacy intervention, two broad aspects of impact on student success must be examined, namely the improvement (if any) in students' academic literacy levels, and the extent to which these abilities are used in and transferred to students' content subjects. However, as Mhlongo (2014) points out, "each tertiary institution faces unique challenges with regard to the specific needs of its students, which makes it essential that specific academic literacy interventions $[\ldots]$ be assessed within the context of addressing such needs". Since academic literacy courses vary vastly in terms of, for example, content and purpose, any evaluation design for assessing their impact would have to be flexible. It is likely that such a design would have to include certain generic components that would address integral aspects that should be part of each academic literacy intervention ${ }^{3}$. However, the researcher would have to be able to adapt some research tools so as to most effectively assess the impact of each individual academic literacy intervention, as not all academic literacy interventions have the same foci or objectives.

This study has provided a broad overview of the instruments that have been used in the literature in assessing the impact of academic literacy interventions. Much more research in this field is necessary though. Future research will have to consider which are the most effective, valid and reliable instruments that could be used in academic literacy impact assessment. Nonetheless, this study hopes to have taken a first step in addressing the research gap in determining the effect of academic literacy interventions.

\footnotetext{
${ }^{3}$ Consider, for example, Van Dyk and Van de Poel's (2013:56) definition of "academic literacy" as "being able to use, manipulate, and control language and cognitive abilities for specific purposes and in specific contexts". Based on this definition, it would be vital that students' abilities to "use, manipulate, and control language and cognitive abilities" would have to be assessed using methods that can be triangulated.
} 


\section{Acknowledgements}

I would like to thank Prof. Tobie van Dyk and Dr Gustav Butler, my PhD supervisors, for their invaluable advice and guidance during the writing of this article.

\section{References}

Archer, A. 2008. Investigating the effect of Writing Centre interventions on student writing. South African Journal of Higher Education 22(2): 248-264.

Bachman, L. and A. Palmer. 2010. Language assessment in practice. Oxford: Oxford University Press.

Beretta, A. 1992. Evaluation of language education: An overview. In C.J. Alderson and A. Beretta (eds). Evaluating second language education. Cambridge: Cambridge University Press. pp. 5-24.

Bharuthram, S. and S. Mckenna. 2006. A writer-respondent intervention as a means of developing academic literacy. Teaching in Higher Education 11(4): 495-507.

Brown, J.D. 2001. Using surveys in language programs. Cambridge: Cambridge University Press.

Butler, G. 2013. Discipline-specific versus generic academic literacy intervention for university education: An issue of impact? Journal for Language Teaching 47(2): 71-88.

Butler, G. and T. Van Dyk. 2004. An academic English language intervention for first year engineering students. Southern African Linguistics and Applied Language Studies 22(1-2): 1-8.

Calderon, A. 2012. Massification continues to transform higher education. Available online: http://www.universityworldnews.com/article.php?story (Accessed 2 May 2013).

Carstens, A. 2011a. Generic versus discipline-specific writing interventions: Report on a quasiexperiment. Southern African Linguistics and Applied Language Studies 29(3): 149-165.

Carstens, A. 2011b. Meaning-making in academic writing: A comparative analysis of pre-and post-intervention essays. Language Matters 42(1): 3-21.

Carstens, A. and L. Fletcher. 2009a. Evaluating the effectiveness of a cross-disciplinary genrefocused writing intervention. Journal for Language Teaching 43(1): 54-65.

Carstens, A. and L. Fletcher. 2009b. Quantitative evaluation of a subject-specific essay-writing intervention. Southern African Linguistics and Applied Language Studies 27(3): 319-332.

Cheetham, J., R. Fuller, G. McIvor and A. Petch. 1992. Evaluating social work effectiveness. Buckingham: McGraw-Hill International.

Cliff, A. 2014. Entry-level students' reading abilities and what these abilities might mean for academic readiness. Language Matters 45(3): 313-324. 
Coxhead, A. 2000. A new academic wordlist. Teachers of English to Speakers of Other Languages (TESOL) 34(2): 213-238.

Davies, A. 2009. Assessing the academic literacy of additional-language students. Southern African Linguistics and Applied Language Studies 27(3): xi-xii.

De Graaff, R. and A. Housen. 2009. Investigating the effects and effectiveness of L2 instruction. In M.H. Long and C.J. Doughty (eds). The handbook of language teaching. Chichester: WileyBlackwell. pp. 726-755.

De Vos, A.S., C.B. Fouché, H. Strydom and C.S.L. Delport. 2011. Research at grassroots for the social sciences and human service professions. Pretoria: Van Schaik.

Defazio, J., J. Jones, F. Tennant and S.A. Hooke. 2010. Academic literacy - The importance and impact of writing across the curriculum. Journal of the Scholarship of Teaching and Learning 10(2): 34-47.

Fouché, I. 2009. Improving the Academic Literacy Levels of First-Year Natural Sciences Students by Means of an Academic Literacy Intervention. Unpublished MA dissertation. Pretoria: University of Pretoria.

Harker, M. and D. Koutsantoni. 2005. Can it be as effective? Distance versus blended learning in a web-based EAP programme. ReCALL 17(2): 197-216.

Higher Education South Africa. 2008. Address to the Parliamentary Portfolio Committee on Education. Available online: http://www.pmg.org.za/files/docs/080624hesa.pdf (Accessed 31 March 2013).

Holder, G., J. Jones, R.A. Robinson and I. Krass. 1999. Academic literacy skills and progression rates amongst pharmacy students. Higher Education Research \& Development 18(1): 19-30.

Hornsby, D.J. and R. Osman. 2014. Massification in higher education: Large classes and student learning. Higher Education 67(6): 711-719.

Howes, A. 2003. Teaching reforms and the impact of paid adult support on participation and learning in mainstream schools. Support for Learning 18(4): 147-153.

Jick, T.D. 1979. Mixing qualitative and quantitative methods: Triangulation in action. Administrative Science Quarterly 24(4): 602-611.

Kasper, L.F. 1997. The impact of content-based instructional programs on the academic progress of ESL students. English for Specific Purposes 16(4): 309-320.

Kern, R. 2000. Literacy and language teaching. Oxford: Oxford University Press.

Kiely, R. 2009. Small answers to the big question: Learning from language programme evaluation. Language Teaching Research 13(1): 99-116. 
Kwiek, M., Y. Lebeau and R. Brown. 2014. Who shall pay for the public good? Comparative trends in the funding crisis of public higher education. Available online: https://repozytorium. amu.edu.pl/jspui/handle $/ 10593 / 9857$ mode $=$ full\&submit simple $=$ Show + full + item + record (Accessed 19 February 2015).

Leibowitz, B. 2010. The significance of academic literacy in higher education: Students' prior learning and their acquisition of academic literacy at a multilingual South African university. Saarbrücken: Lap Lambert.

Lynch, B.K. 1996. Language program evaluation: Theory and practice. Cambridge: Cambridge University Press.

Lynch, B.K. 2003. Language assessment and programme evaluation. Edinburgh: Edinburgh University Press.

Mhlongo, G. 2014. The Impact of an Academic Literacy Intervention on the Academic Literacy Levels of First Year Students: The NWU (Vaal Triangle Campus) Experience. Unpublished MA dissertation. Potchefstroom: North-West University.

Murie, R. and R. Thomson. 2001. When ESL is developmental: A model program for the freshman year. In J.L. Higbee (ed.) 2001: A developmental odyssey. Warrensburg: National Association of Developmental Education. pp. 15-28.

Newcomer, K.E., H.P. Hatry and J.S. Wholey. 2010. Planning and designing useful evaluations. In J.S. Wholey, H.P. Hatry and K.E. Newcomer (eds). Handbook of practical program evaluation. San Francisco: Jossey-Bass. pp. 5-29.

Ngoepe, L.J. 2007. The University of Limpopo Mathematics and Science Foundation Year Course in English and Study Skills: An Evaluation. Unpublished PhD dissertation. Polokwane: University of Limpopo.

Parkinson, J., L. Jackson, T. Kirkwood and V. Padayachee. 2008. Evaluating the effectiveness of an academic literacy course: Do students benefit? Per Linguam 24(1): 11-29.

Scott, I., N. Ndebele, N. Badsha, B. Figaji, W. Gevers and B. Pityana. 2013. A proposal for undergraduate curriculum reform in South Africa: The case for a flexible curriculum structure. Pretoria: Council on Higher Education.

Song, B. 2006. Content-based ESL instruction: Long-term effects and outcomes. English for Specific Purposes 25(4): 420-437.

Storch, N. and J. Tapper. 2009. The impact of an EAP course on postgraduate writing. Journal of English for Academic Purposes 8(3): 207-223.

Teichler, U. 1998. Massification: A challenge for institutions of higher education. Tertiary Education \& Management 4(1): 17-27. 
Terraschke, A. and R. Wahid. 2011. The impact of EAP study on the academic experiences of international postgraduate students in Australia. Journal of English for Academic Purposes 10(3): 173-182.

Thompson, J.L. 2011. An Evaluation of a University Level English for Tourism Program. Unpublished MA dissertation. Chiang Mai: Payap University.

Van Dyk, T., K. Cillié, M. Coetzee, S. Ross and H. Zybrands. 2011. Ondersoek na die impak van 'n akademiese geletterdheidsintervensie op eerstejaarstudente se akademiese taalvermoë. LitNet Akademies 8(3): 487-506.

Van Dyk, T. and K. Van de Poel. 2013. Towards a responsible agenda for academic literacy development: Considerations that will benefit students and society. Journal for Language Teaching 47(2): 43-69.

Van Dyk, T., H. Zybrands, K. Cillié and M. Coetzee. 2009. On being reflective practitioners: The evaluation of a writing module for first-year students in the Health Sciences. Southern African Linguistics and Applied Language Studies 27(3): 333-344.

Van Rooy, B. and S. Coetzee-Van Rooy. 2015. The language issue and academic performance at a South African university. Southern African Linguistics and Applied Language Studies. Available online: http://dx.doi.org/10.2989/16073614.2015.1012691 (Accessed 24 March 2015). Printed publication forthcoming.

Van Wyk, A.L. and W.J. Greyling. 2008. Developing reading in a first-year academic literacy course. Stellenbosch Papers in Linguistics 38: 205-219.

Weideman, A. 2003. Academic literacy: Prepare to learn. Pretoria: Van Schaik.

Winberg, C., J. Wright, B.W. Birch and C. Jacobs. 2013. Conceptualising linguistic access to knowledge as interdisciplinary collaboration. Journal for Language Teaching 47(2): 89-107.

Yeld, N. 2010. Some challenges and responses: Higher education in South Africa. Discourse 38(1): 24-36. 